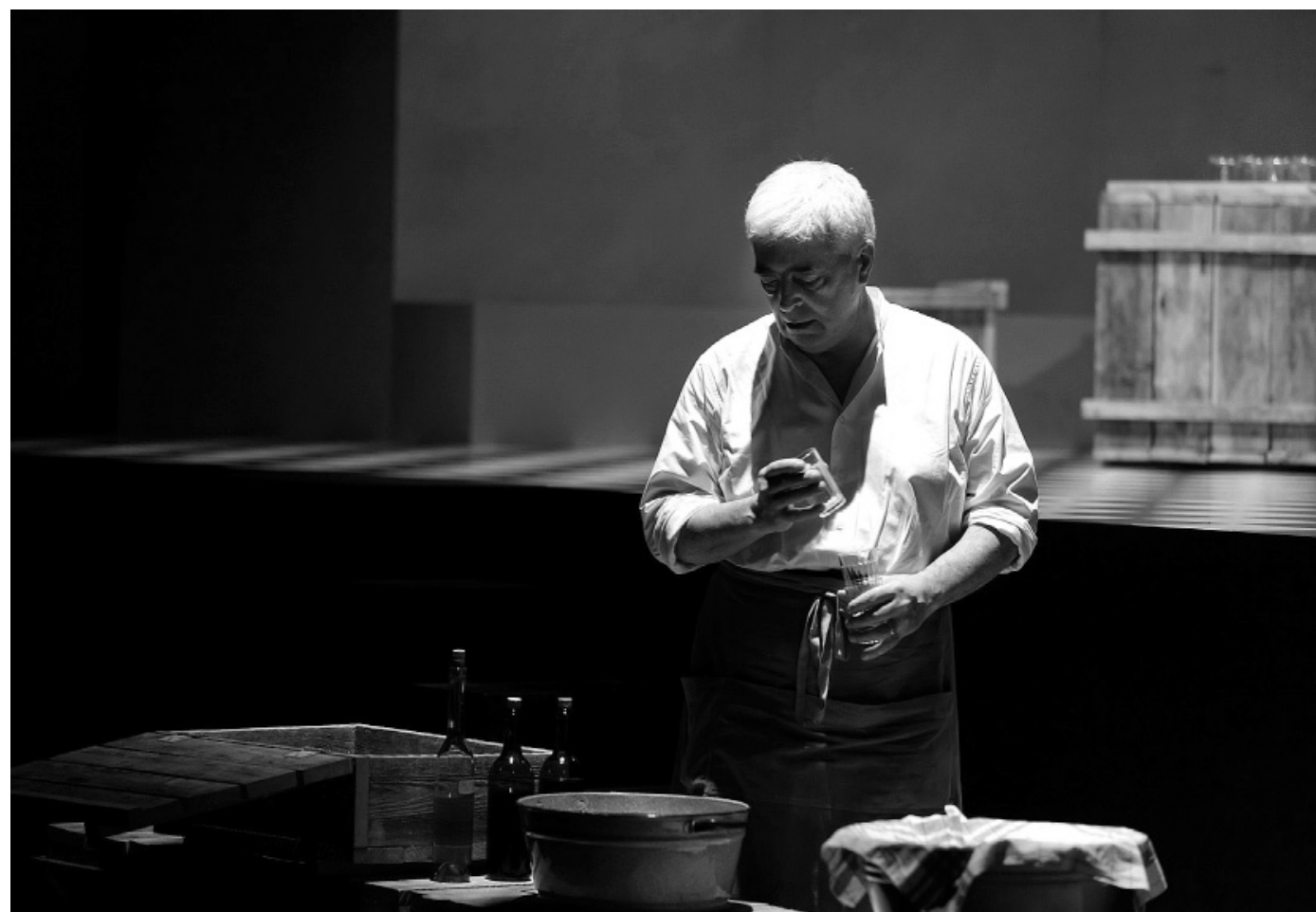

\title{
Quando as cerejas estiverem maduras
}

\section{Sebastiana Fadda}

Titulo: A Cacatua Verde (1898). Autor: Arthur Schnitzler. Tradução: Frederico Lourenço. Encenação:Luis Miguel Cintra. Cenário e figurinos: Cristina Reis. Desenho de luz: Daniel Worm d'Assumpção. Interpretação:Alice Medeiros, António Fonseca, Catarina Lacerda, Cleia Almeida, Dinis Gomes,

Duarte Guimarães, Gonçalo Amorim, Joana de Verona, João Grosso, João Villas-Boas, José Manuel Mendes, Luis Lima Barreto, Luis Miguel Cintra, Miguel Loureiro, Miguel Melo, Neusa Dias, Nuno Casanovas, Ricardo Aibéo, Rita Blanco, Rita Loureiro, Sofia Marques, Tiago Manaia, Tiago Matias, Tobias Monteiro, Victor d' Andrade. Co-produção:Teatro Nacional D. Maria II e Teatro da Cornucópia. Local e data de estreia: Teatro Nacional D. Maria II, Sala Garrett, Lisboa, 17 de Fevereiro de 2011.

Pelo que consta na CETBase ${ }^{1}$, é apenas a partir dos anos Oitenta do século XX que a obra de Arthur Schnitzler surge em palcos portugueses. A mais concorrida, Dança de roda / La ronde (Reigen, 1896/7), foi várias vezes

traduzida e encenada, enquanto as outras - a sequência num acto Anatol (1893), a comédia em três actos Os jornalistas (Fink und fliederbusch, 1916, editada pela Cotovia com o título Pintassilgo e Pimpinela) e o drama 0 caminho solitário (Der einsame Weg, 1904) - receberam atenções pontuais. Eduarda Dionísio, Maria Adélia Silva Melo, Anabela Mendes, Rogério de Carvalho, Pedro Penim, Christine Laurent, Teatro Nacional D. Maria II, Teatro Praga, Teatro da Cornucópia, são apenas alguns dos nomes e das companhias associadas ao percurso do autor austríaco em Portugal. Mas se a escrita deste sempre ficou dividida entre narrativa e dramaturgia, não faltou nos nossos

palcos a fusão dos géneros de gosto pós-moderno, devido às adaptações das novelas Morrer (Sterben, 1892), 0 sonho (Traumnovelle, 1926) e A menina Else (Fräulein Else, 1924), a primeira e a terceira por José Maria Vieira Mendes, a segunda pelo jovem Projecto Novos Actores.

Austríaco como Sigmund Freud e seu contemporâneo, filho de um médico famoso, também Schnitzler estudou medicina, ficando fascinado pela psiquiatria e fazendo confluir na sua obra as teorias psicanalíticas ainda em gestação, criando personagens com frequência aprisionadas na sua própria intimidade e a que os leitores e/ou espectadores têm acesso pela corrente da consciência (stream of consciousness) através da qual se expressam em monólogo interior, feito de fluxos e refluxos da consciência e do inconsciente. Nos diálogos, pelo contrário, as falas são breves e ágeis, sintéticas e frias, a fim de transmitirem a visão distanciada e irónica do autor, que faz uma radiografia precisa da psicologia das suas criaturas, das contradições da mente humana e das influências nela dos instintos sexuais, escamoteando as hipocrisias, frivolidades e perversões duma sociedade de aparência respeitável e de substância em decomposição.

0 olhar analítico do cientista e a finura elegante do escritor aliam-se ao perplexo desencanto do perspicaz observador da história e da arte - bem como do lugar que ambas têm na vida das pessoas - na peça Der grüne Kakadu (1898), levada à cena com o título A Cacatua Verde pelo Teatro da Cornucópia, numa co-produção com o Teatro Nacional D. Maria II, com tradução de Frederico Lourenço e encenação de Luís Miguel Cintra. A

singularidade do espectáculo resultou da feliz conjugação dos elementos contidos no texto com a leitura dramatúrgica 
A Cacatua Verde de Arthur Schnitzler, enc. Luis Miguel Cintra, Teatro da Cornucópia, 2011 (Neusa Dias, Joana de Verona, Alice Medeiros), fot. José Manuel Furtado. do mesmo, pelo que todos os sentidos, evidentes e latentes, ficaram amplificados, esticados até ao limite, levados a potenciar exponencialmente os referentes, esbatendo ainda mais as lábeis fronteiras entre texto e cena, arte e vida, verdade e mentira, história colectiva e história individual, acção consciente e pulsão erótica, tempo representado e tempo da representação, atingindo um raro grau de incandescência, transcendendo épocas e interpelando crítica e lucidamente a História e a Arte, deixando em aberto o diálogo entre as duas, bem como entre autor e encenador. Isto é, as ambiguidades e os questionamentos proliferam a partir do texto e do autor e, agarrados pelo encenador, multiplicam-se e fundem o discurso dos dois numa partitura cénica em que reverberam motivos e tensões variadas, com destaque para a fragmentação modernista da personalidade e as ambivalências entre máscara e rosto. Assim sendo, nesta peça de Schnitzler encontram-se os prenúncios e as inquietações contidas em A máscara e o rosto (La maschera e il volto, 1913), de Luigi Chiarelli, peça-manifesto do "teatro do grotesco", e em Seis personagens à procura de autor (Sei personaggi in cerca d'autore, 1921), de Luigi Pirandello, "comédia por fazer" que abre a trilogia do "teatro no teatro". Porém, na sua concretização cénica, inserem-se as reflexões de Luís Miguel Cintra sobre outro tempo e outro teatro - os nossos -, pelo que o espectador é colocado perante uma companhia e um encenador fictícios (Prospère e a Cacatua Verde) em cujo percurso se enxerta o duma companhia e dum encenador reais

(Cintra e a Cornucópia). Metateatro, por certo, mas também muito mais.

No texto, Schnitzler escolhe fazer desenrolar a acção da peça numa taberna, A Cacatua Verde, na noite entre 13 e 14 de Julho de 1789, data da tomada da Bastilha. 0 espaço situa-se numa cave, onde Prospère, o dono e taberneiro, ex-director duma companhia de teatro, dirige os seus actores, que fingem ser malfeitores e não passam de artistas ou pobre diabos, representando para os seus clientes, aristocratas ociosos que, do alto da sua posição de exploradores impunes de que supostamente não têm consciência, querem experimentar o arrepio da proximidade com a escória da sociedade como se de um safari urbano para ver animais exóticos, supostamente perigosos e supostamente domesticados, se tratasse. Na verdade, mais do que histórica, a peça é uma charada psicológica e metateatral, porque é no espaço concreto de um teatro

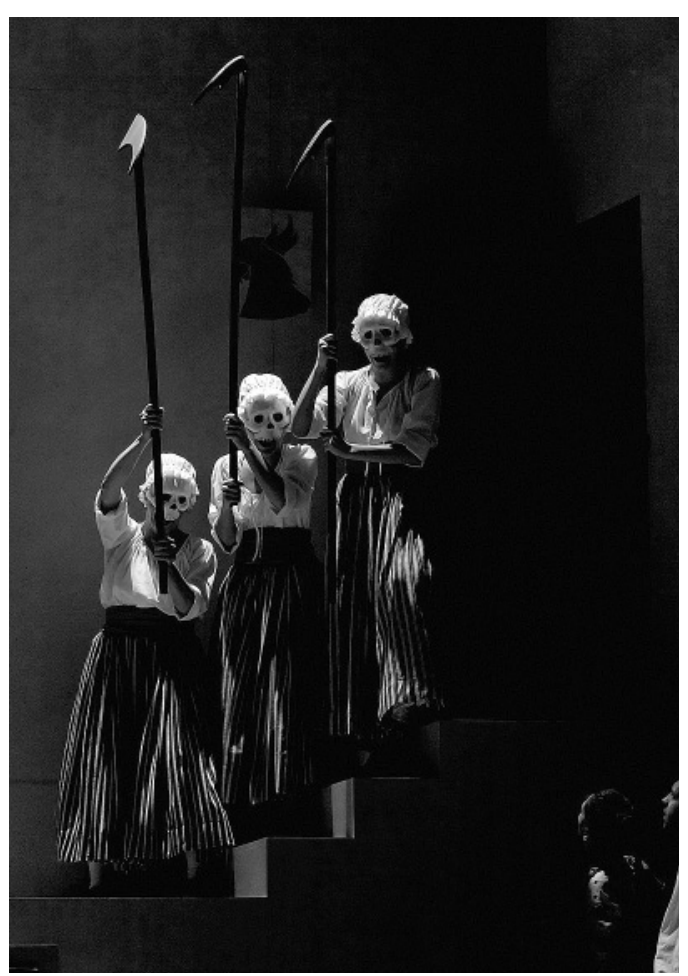

dentro de outro teatro que surgem constantemente as perguntas "quem é quem", "quem é o quê", "o que é o quê" e "como fazer o quê"? É um jogo, portanto, inclusive das perguntas, também sobre os géneros dramáticos e a arte de representar. Cabem, deste modo: a comédia risivel das convenções sociais, onde se escarnecem os modelos do teatro espanhol seiscentista de capa e espada (v. as escaramuças dos actores e a faca verdadeira do taberneiro), as inflamações românticas de curta duração (v. o ciúme cego de Henri e o sonho pueril de controlar a esposa refugiando-se num idílico campo, ao abrigo das corrupções citadinas), os vestígios da tragédia à mistura com os do melodrama de estragos e reviravoltas fáceis (v. os avisos regulares de algo de terrivel e iminente a pairar sobre as personagens, anunciados por Henri acerca da prenda de casamento e despedida do palco memoráveis); o grotesco da voz estrídula da marquesa que grita um inesperado "viva a liberdade", intempestivo e de sentido deslocado (i.e., enquanto os sans-culotte perseguem ideais emancipadores e pão, essa mulher, que nasceu nobre por acaso, procura apenas a libertinagem para soltar os instintos reprimidos); a irónica leveza com que se apresenta a pompa vazia da literatura e da retórica, revoluccionária ou não (v. os oportunismos dos oradores de turno e dos literatos de salão); a mentira do novo poder instituído, que transforma um crime passional num acto de heroismo patriótico para seu uso e consumo (num ápice, Henri passa de assassino comum a herói revolucionário). E cabem, ainda: a identificação entre arte e vida (o assassinio confessado na recitação deverá ser consumado); a dissociação entre arte e vida (no palco a única realidade é a da representação); a labilidade identitária das personagens (os carrascos de hoje são as vítimas de amanhã e vice-versa); a inércia da Arte e a tragédia da História (enquanto na taberna de Prospère e na Sala Garrett do Teatro Nacional se brinca evadindo a realidade, lá fora, nas ruas de Paris e algures no mundo, há quem 


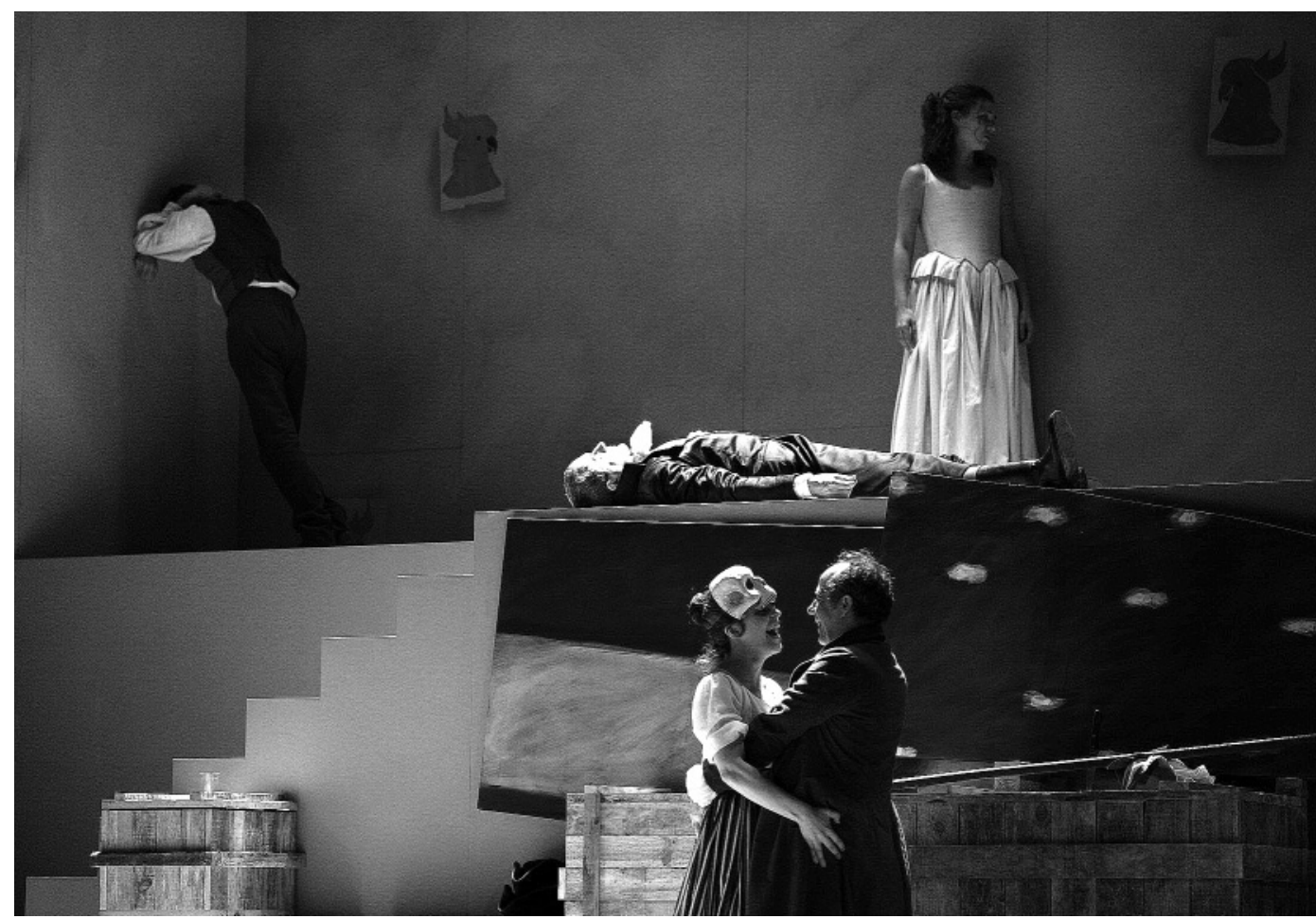

A Cacatua Verde, de Arthur Schnitzler, enc. Luis Miguel Cintra, Teatro da Cornucópia 2011 (Ricardo Aibéo, João Grosso, Rita Loureiro, Catarina Lacerda, António Fonseca), fot. Rui Gregório. lute pela afirmação do direito de viver e não apenas de sobreviver). Os níveis de leitura, porém, não se esgotam aqui.

No espectáculo, Luis Miguel Cintra rejeita a ilusão do palco à italiana deixando a cena e os actores à vista, num fundo preto onde tudo pode ficar inscrito, ele de camisa branca, calças e avental escuro, o resto do elenco de fatomacaco, todos a cantar La carmagnole, canção revolucionária emblema da revolução francesa e de autor anónimo, composta em 1792 e cuja fórmula musical terá talvez origem numa dança piemontesa da vila de Carmagnola. Este prólogo, pertinente mas de certo modo abusivo, é um dos vários elementos dissonantes do espectáculo, pois quebra a linearidade temporal dos acontecimentos e subverte-os, anunciando deste modo um evento que ainda há-de vir enquanto devia já ter passado, mas criando uma ponte com o final do espectáculo, que encerra com outra canção, também abusiva, com texto assinado por Jean-Baptiste Clément em 1866 e musicado por Antoine Renard em 1868, associada à Comuna de Paris, alusão igualmente ausente no texto de Schnitzler, Le temps des cerises, cuja versão rock e enraivecida de Bertrand Cantat e do grupo Noir Désir, ligada a ritmo ensurdecedor, nos atira para este nosso tempo tão desesperançado. Dito por outras palavras, o fato-macaco dos futuros agentes da revolução burguesa de 1789 insinua o tempo das cerejas de 1871, em que se deu a revolução proletária. Esta, por sua vez, ao interpelar-nos a nós, espectadores do principio do século XXI, obriga-nos a questionar a nossa atitude perante o nosso tempo, galvanizando os nossos anseios por novos rumos que auspiciam todo o desejo de mudança, mas apertando-nos com um nó na garganta por sabermos de antemão que toda a revolução naufraga numa contrarevolução, na implementação do sistema da Terreur ou na repressão dos massacres da Semaine sanglante. Isto é, o desejo de justiça desemboca na injustiça, misturando e derramando indiscriminadamente o sangue dos ímpios e o dos rectos. Mas se esta visão parece sugerir que a história ciclicamente se repete e sempre nos atira para um círculo vicioso do qual nunca sairemos, consola-nos a convicção de que, em tempo nenhum, os acontecimentos se repetem iguais: permanecem elementos e motivações, mas a sua configuração, as tensões e as forças em jogo nunca são as mesmas, pelo que nos cabe, isso sim, a responsabilidade de encontrar novas soluções para velhos e novos problemas, nunca desistindo da aspiração à implementação efectiva de maior justiça social. Aquelas que aparentavam ser liberdades dramatúrgicas, afirmamse então como pertinentes e necessárias, adequadas para fins de amplificação das ressonâncias do texto, integradas com coerência no registo do autor.

Refira-se que, em termos de estética teatral, para o autor como para o encenador, o eixo fulcral que rege 0 texto e o espectáculo tem a ver com o princípio da verosimilhança: o real pode ser reconhecido no verosimil, o que é verosímil pode passar a ser real. Máscara e Rosto, ambos falsos e verdadeiros ao mesmo tempo, são faces da mesma moeda. Tal como a Morte e a Revolução, que nesse intrusivo amplexo final, estranho ao texto mas da lavra do dramaturgo Heiner Müller e extraido de A missão (Der Auftrag, 1979), declaram ser uma a máscara da outra, pretendendo demonstrar que o instinto vital contém uma pulsão de morte e que não há morte que não ambicione a redenção num renascimento.

Belo, equilibrado, acertado e altamente significativo do ponto de vista semiótico, o cenário de Cristina Reis coloca-se ao serviço da proposta dramatúrgica do encenador com uma inteligência e economia de meios notáveis. Quando é retirado o pano preto que de início oculta o cenário, o público fica perante uma estrutura quase perfeitamente simétrica: do meio para baixo uma escadaria em "V" que dá para o fosso da orquestra; do meio para cima uma escadaria em "V" ao contrário que permite a criação do palco no palco, no qual se irá exibir 


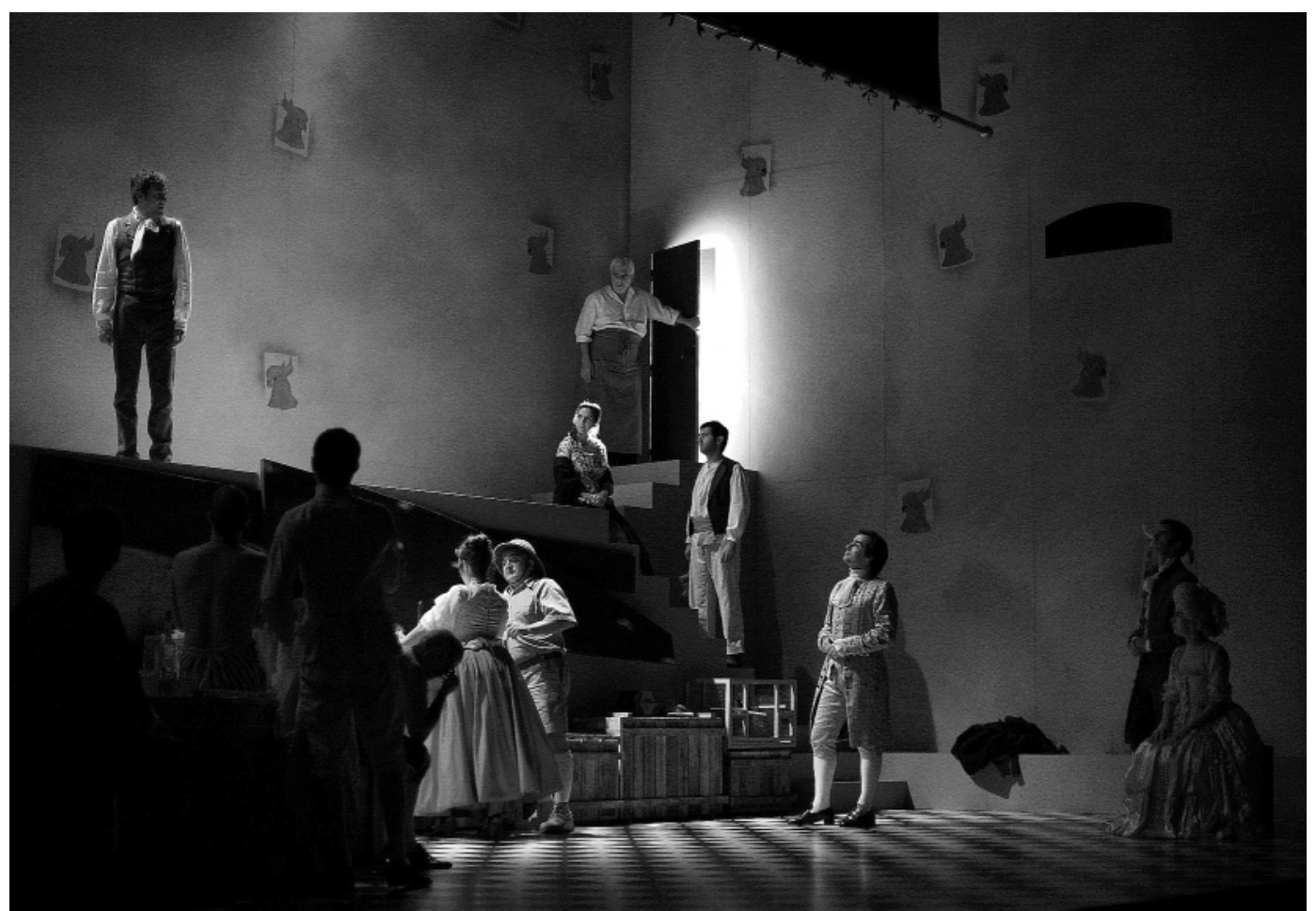

Henri no seu "a solo" de herói e actor romântico; do meio para a esquerda e do meio para a direita, novamente uma construção em espelho, dois "Vs" deitados, "<>", que criam outra simetria, mesmo que imperfeita devido às diversas proporções das escadarias em questão. Será abusivo falar-se em imaginária e simbólica rosa-dosventos, em cujos vértices Norte e Sul se encontram o Paraíso da Arte e o Inferno da Vida, e vice-versa, e em cujos vértices Oeste e Leste se intersecciona o Purgatório do Palco e da Realidade? É evidente que a simetria remete para o equilibrio tal como concebido pela arquitectura clássica e barroca, de cujas fachadas de certos palácios imponentes, aliás, a dupla escadaria aqui revisitada é memorando. A este respeito, como esclareceu Luís Migue Cintra num encontro com o público, no último dia de representação do espectáculo, este elemento é funciona para outras finalidades - nomeadamente, a criação dum cenário dentro do cenário, a sugestão da escadaria presente nas revistas à portuguesa, a possibilidade de aumentar a tensão dramática devido às directrizes opostas que podem ser percorridas pelos intérpretes -, mas a especulação não deixa de ser aliciante, arrastando outras perguntas e ilações. Como por exemplo: Prospère, situado no lugar do Maestro e a servir vinho, não encarnará Dioniso que orquestreia os movimentos dos seus actores nas suas orgias dionisiacas? E não será igualmente o demiurgo marionetista que irá manipular e tornar credivel a representação de Henri, exaltado pela paixão e pela arte, isto é, pela carne e pela alma, no ápice do espectáculo no espectáculo, quando todos, público na sala e público no palco, num perfeito quadro de mise en abîme, ficam suspensos ignorando onde começa a realidade e acaba a ficção e vice-versa? E as mulheres, que entram de foice um tabuleiro onde se jogam os destinos humanos individuais e colectivos? E a gaiola, à direita, não é a mesma onde todos ficamos presos, esperando e aspirando à liberdade, ansiando por aquele céu azul pintado no alto da caixa cénica? E que dizer da eloquência da partitura luminotécnica, que associa os tiros dos canhões aos relâmpagos, libertadores da electricidade no ar, aclarando e escurecendo a cena, dando sinais alternados de vida e de morte? Ou então quando ilumina a dupla Prospère Henri, na sua magistral contracena, esbatendo tudo à volta para realçar o zénite da ambiguidade deste momento impar de teatro?

Muitas, por certo, são as hipóteses que texto e espectáculo permitem formular e que aqui não foram contempladas. Mencione-se, mesmo que de passagem, a relevante continuidade da pesquisa do Teatro da Cornucópia, que prossegue com coerência a

(auto)questionação do seu percurso e a do discurso ético e estético perseguido em espectáculos tão diversos, mas ligados pelo mesmo fio condutor - o mencionado A missão (1984 e 1992), de Heiner Müller; o encantatório e evanescente Os gigantes da montanha (2008), de Luigi Pirandello; o austero e soturno Miserere (2010), com base em Gil Vicente; o soberbo e exemplar A cidade (2010), com base em Aristófanes -, bem como a sua concepção da função crítica do teatro e do seu entendimento como lugar e expressão do colectivo. Merece, pois, a maior admiração todo o elenco, que transportou para a cena o sentimento de trabalho em conjunto, pelo que todos os actores contribuíram com generosidade para o êxito do resultado, acabando por participar num "concertato"2 conseguido, seguro e reconfortante, por contrariar o individualismo militante das sociedades actuais. Reiterese, então, a urgência e oportunidade da pergunta "maior" que, para além de todas as dúvidas, relativismos e falta de certezas, o texto e o espectáculo colocam: nós, em que espaço e em que tempo estamos e/ou queremos estar? 